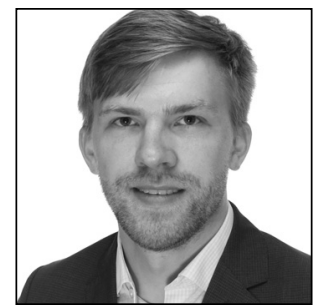

Märt Maarand

\title{
The Concept of Recovery of Credit Institutions in the Bank Recovery and Resolution Directive
}

\section{Introduction}

The recovery and resolution framework created by the Bank Recovery and Resolution Directive (BRRD) ${ }^{*_{1}}$ is in essence a final safety net for failing credit institutions that gives the public authorities more powers to intervene in such an institution's operations to save it and, if needed, restructure that institution by force. Correspondingly, the credit institutions themselves have been assigned further responsibilities. The name of the BRRD suggests that it covers two sets of legal activities - both recovery and resolution of credit institutions. However, while resolution is clearly defined in the BRRD's Article 2(1)(1), the directive does not define the concept of recovery. Therefore, it is not actually clear whether recovery could or should be treated as a separate concept under the BRRD; which elements it encompasses; and how these elements enhance the pre-existing prudential regulation, processes and tools.

There have not been many pieces of research aimed at delineating recovery as a concept separate from resolution and from what is addressed in prudential legislation. Therefore, this article highlights the associated aims and objectives, along with the connections among them, the system they compose, and the coherence of the relevant norms. Where suitable, it offers comparison of the provisions considered with the provisions of harmonised European Union (EU) prudential legislation.

The aim of this article is to distinguish the concept of recovery of credit institutions from resolution of credit institutions and the pre-existing prudential framework. This is done by identifying and examining the elements, as well as the powers provided to public authorities ${ }^{{ }^{2}}$, that can be considered constituent to the concept of recovery. The problem is that if recovery is to be deemed a differentiable concept, some or even all of the legal rules and principles applicable within the prudential or resolution framework might not applicable in the context of recovery, and vice versa. There might be specific legal principles applicable only with regard to recovery, or, if not, these may be developed in the future. If powers connected with the

Directive 2014/59/EU of the European Parliament and of the Council of 15 May 2014 establishing a framework for the recovery and resolution of credit institutions and investment firms [2014] OJ L 173/190.

2 The legislation distinguishes between competent authorities, responsible for the prudential supervision, and resolution authorities, responsible for resolution. These may, de facto, be the same authority on national level. See the BRRD's Art. 2(1) (21), Art. 3(1), Art. 3(3), and Recital 15; Regulation (EU) No. 575/2013 of the European Parliament and of the Council of 26 June 2013 on prudential requirements for credit institutions [2013] OJ L 176/1 (the Capital Requirements Regulation), Art. 4(1)(40). 
concept of recovery are to be exercised by the authorities, the question of following appropriate rules and principles has a direct connection with state liability. Also, it could be technically less complicated to lay down legal requirements or rules for specifically dealing with only the recovery process, while also granting the powers related to recovery as a whole to new or other authorities, should this be needed. Although these topics beyond differentiating the recovery framework from the resolution and prudential ones do not strictly belong to the scope of this article, defining the limits of recovery should lay solid groundwork for examining these topics in depth in the future.

The starting point for the article is the proposition that recovery can be distinguished as a differentiable concept in the BRRD. Recovery could be handled as a distinguishable stage and a set of actions in the regulatory structure consisting of two connected phenomena - recovery planning and early intervention measures. Accordingly, the article employs the following structure: The distinction of recovery as a concept of its own is dealt with in the first main section, and each phenomenon is then dealt with in its own section. Recovery planning and its main principles are covered in the second main section, and early intervention measures and how these broaden the powers of the authorities are examined in the final one.

\section{Recovery of a credit institution as a differentiable concept}

While according to Recital 7 to the Capital Requirements Regulation and Recital 34 to the Capital Requirements Directive (CRD IV) ${ }^{*}$ the main overall goal of prudential supervision is to ensure financial stability by, among other things, avoiding insolvency of credit institutions, it is nonetheless obviously inevitable that regulations, regulators, and institutions themselves cannot assure that no credit institution ever nears or reaches insolvency. The BRRD and the Single Resolution Mechanism (SRM) Regulation ${ }^{*}$, together with relevant EU and national law, deal with these situations beyond the 'normal' - preparation for upcoming crisis; early intervention; and, if needed, as it is described by the Single Resolution Board, ensuring orderly resolution of failing banks with minimal costs for taxpayers and to the real economy. ${ }^{*} 5$ The European Parliament has accurately stated that, while the BRRD sets the framework for all banks in the European Union, the SRM Regulation defines the unified resolution procedure for institutions within the euro area and constitutes the second pillar of the banking union. ${ }^{*}$ One can state in summary that recovery stands somewhat in between the pre-existing conventional financial supervision system, on one hand, and the resolution system, on the other - laying obligations on the relevant businesses and extending competent authorities' powers in situations beyond the normal but immediately preceding possible resolution processes.

According to the summary of impact assessment for the proposal of a BRRD, the first objective of the bank recovery and resolution framework was to ensure that bank failures are avoided as far as possible and that the authorities and banks are prepared for adverse developments. ${ }^{*}$ It has been proposed that, to reduce the chances of the resolution-stage mechanisms needing to be invoked, it is important for actions in the resolution stage to be complemented by a phase of heightened supervisory involvement. ${ }^{* 8}$

3 Directive 2013/36/EU of the European Parliament and of the Council of 26 June 2013 on access to the activity of credit institutions and the prudential supervision of credit institutions and investment firms [2013] OJ L 176/338.

4 Regulation (EU) No 806/2014 of the European Parliament and of the Council of 15 July 2014 establishing uniform rules and a uniform procedure for the resolution of credit institutions and certain investment firms in the framework of a Single Resolution Mechanism and a Single Resolution Fund [2014] OJ L 225/1 (SRM Regulation).

5 This involves the Single Resolution Mechanism (SRM). See “The SRM: A European Solution for Ending "Too Big to Fail”, available at https://srb.europa.eu/en/content/single-resolution-mechanism-srm, accessed on 30 April 2019.

6 See Andrej Stuchlik, 'Amending the Bank Resolution Framework - BRRD and SRMR', EU Legislation in Progress Briefing, First Edition, 6 June 2017, p. 2. Available at http://www.europarl.europa.eu/RegData/etudes/BRIE/2017/603958/ EPRS_BRI\%282017\%29603958_EN.pdf, accessed on 30 April 2019.

7 European Commission, 'Summary of the Impact Assessment Accompanying the Document Proposal for a Directive of the European Parliament and of the Council Establishing a Framework for the Recovery and Resolution of Credit Institutions and Investment Firms and Amending Council Directives 77/91/EEC and 82/891/EC, Directives 2001/24/EC, 2002/47/ EC, 2004/25/EC, 2005/56/EC, 2007/36/EC and 2011/35/EC and Regulation (EU) No 1093/2010', SWD (2012) 167 final, p. 3 .

8 See Martin Čihák, Erlend Nier, 'Resolving Problem Banks: A Review of the Global Evidence' in Charles Goodhart et al. (eds), Central Banking at a Crossroads: Europe and Beyond (Anthem Press 2014), p. 114. - DOI: https://doi.org/10.26530/ oapen_626351. 
Although the term is prominent in the title, it is not quite clear what is meant by 'recovery' for credit institutions in the BRRD. The BRRD does not clearly define what this recovery is, nor is it specified as a goal or a process or with regard to what elements it consists of. On one hand, the credit institution's recovery may be understood to be an overall goal for the processes covered by the BRRD, not a distinct phase as such, but there might be another feasible and quite appropriate interpretation. In a situation wherein regulatory requirements and prudential supervision have failed to have the desired effect, recovery could be understood as a process and as the first phase of dealing with a credit institution faced with immediately foreseen troubles or problems that are already hampering the institution with the aim of avoiding failure.

Recitals 1 and 12 to the BRRD refer to a recovery and resolution framework; likewise, Recital 6 mentions recovery and resolution tools in the same breath. It could be argued that this indicates, perhaps even expressly, an intention to distinguish between recovery and resolution as two separate stages and processes covered by the BRRD. Also, as will be examined below, recovery plans are important elements of the framework in question. It would be against all logic to regulate a plan for something that does not exist. If recovery is indeed a stage or a process of its own, what does it consist of?

According to the impact assessment accompanying the BRRD proposal, three key stages need to be considered in the context of a bank recovery and resolution framework: (i) preparation and prevention, (ii) early intervention, and (iii) resolution. ${ }^{*}{ }^{*}$ If recovery is to be considered a distinguishable phase, does this entail a recovery phase composed simply of preparation, prevention, and early intervention stages? The recitals generate even more confusion in respect of the relation between early intervention and recovery. In Recital 39 to the BRRD, recovery and early intervention are presented as separate phases. At the same time, Recital 22 states that the recovery plan should cover measures to be taken by the management of the institution where the conditions for early intervention are met and therefore indicates that early intervention could be part of the recovery phase.

Let us begin by considering the three-way split referred to above. In the European Commission's eyes, the two aspects of the first of the three stages - preparation and prevention - are distinct elements together aiming to prevent the development of a crisis. ${ }^{*}{ }^{*}$ Under this concept, the preparation includes a voluntary intra-group financial support agreement framework and contingency planning, while the prevention powers are intended for ensuring that banks are resolvable in the event of failure. ${ }^{* 11}$ Indeed, Title II of the BRRD covers just such a preparation phase in its first three chapters, respectively, with that phase including recovery planning and resolution planning, questions of resolvability, and intra-group financial support. As for the second element, the crisis prevention measures are specified, in Article 2(101) of the BRRD, to be the exercise of powers to direct removal of deficiencies or impediments to recoverability under Article 6(6); the exercise of powers to address or remove impediments to resolvability under Articles 17 or 18; application of an early intervention measure under Article 27; appointment of a temporary administrator under Article 29; and exercise of the write-down or conversion powers under Article 59.

That early intervention measures are encompassed by the concept of recovery is not explicitly evident from the text of the BRRD, and different interpretations are possible. For example, in Estonian national legislation, the regulation covering recovery planning is structurally part of the prevention measures ${ }^{*}{ }^{12}$ while early intervention is addressed in the chapter dealing with resolution planning. ${ }^{* 13}$ It is visible from the impact assessment for the BRRD proposal that the goal behind introducing new powers of the authorities, denoted as early intervention measures, was to develop the existing framework further so that supervisors would be able to intervene at an even earlier stage and would be equipped with an expanded list of tools and powers designed to prevent the further deterioration of financial difficulties in banks. ${ }^{*}{ }^{*}$ Crucially, however,

9 European Commission, 'Impact Assessment Accompanying the Document Proposal for a Directive of the European Parliament and of the Council Establishing a Framework for the Recovery and Resolution of Credit Institutions and Investment Firms and Amending Council Directives 77/91/EEC and 82/891/EC, Directives 2001/24/EC, 2002/47/EC, 2004/25/EC, 2005/56/EC, 2007/36/EC and 2011/35/EC and Regulation (EU) No 1093/2010', SWD (2012) 166 final (Impact Assessment), p. 12.

10 Ibid., p. 60.

11 Ibid.

12 Finantskriisi ennetamise ja lahendamise seadus (Financial Crisis Prevention and Resolution Act). RT I, 19.03.2015, 3, 52; RT I, 13.03.2019 (in Estonian; English text available at https://www.riigiteataja.ee/en/eli/501042019019/consolide, accessed on 30 April 2019), Chapter 2, Division 1.

13 Ibid., Chapter 3, Division 3.

14 Impact Assessment (see Note 9), p. 60. 
the implementation of recovery plans is directly bound to the early intervention measure of right to require implementation of arrangements or measures set out in the recovery plans, as laid out in Article 27(1)(a) of the BRRD. ${ }^{*}{ }^{15}$ This clearly indicates that the early intervention stage should be considered a central part of recovery of a credit institution.

Let us return to the crisis prevention measures listed earlier in the article. While Article 6(6) of the BRRD deals with deficiencies in recovery plans, articles 17 and 18 cover powers to remove or otherwise address impediments to resolvability, and Article 59 deals with one of the resolution tools that is quite clearly part of resolution and resolution planning, articles 27 and 29 seem to have another purpose. The latter two articles of the BRRD are structured as part of the early intervention regulations, which means that the crisis prevention phase and early intervention overlap with each other at least partially. The preparation and prevention involve both the recovery and the resolution part of the framework, while early intervention measures form one component of crisis prevention measures. From this it can be concluded that the proposed three-stage division intended by the directive's authors is more a description of the order of steps, and it does not give us a satisfactory explanation of the differences among prudential supervision, recovery, and resolution. Nonetheless, early intervention could be considered to fall under the recovery concept.

On the other hand, recovery can be separated from the prudential supervision and resolution process in terms of function. The preparation and prevention were designed to be part of ongoing supervision by authorities. ${ }^{* 16}$ On the recovery side, this design was intended to include introduction of recovery plans and supervision of these plans designed to ensure that banks have strategies in place that enable them to take early action to restore their long-term viability in the event of material deterioration of their financial situation. ${ }^{*}{ }^{* 17}$ With regard to resolution, the approach was meant to include the preparation of resolution plans that would set out options for resolving the institution. ${ }^{*} 18$ As can be seen from articles 27(1) and 2(1)(21), the recovery planning and early intervention measures are placed at the disposal of competent authorities, while, according to Articles 2(1)(18), 2(1)(19), 2(1)(20), 2(1)(102) and Title IV of the BRRD, the powers and tools for dealing with crisis management and resolution are entrusted to the resolution authority. When an action beyond the usual ongoing supervision is needed, the early intervention measures come into play from the recovery side, while resolution as a separate concept is the purview of the resolution authority. Even if some elements are grouped or defined differently in some states, the functions' distinction remains intact.

It can be concluded that the recovery of a credit institution in the meaning of the BRRD can be distinguished by function as, on the institution's side, drawing up and following recovery plans and, on the authorities' part, conducting supervision over recovery planning and employing early intervention measures. From here, one can take a closer look at the two elements of the recovery system for credit institutions.

\section{Recovery planning}

\subsection{The core principles of recovery planning}

According to Article 5(1) of the BRRD, institutions not part of a group subject to consolidated supervision are required to draw up and maintain a recovery plan providing for measures to be taken by the institution to restore its financial position following a significant deterioration of its financial situation. ${ }^{*}{ }^{*}$ Article 5(2) of the BRRD sets the requirement that the institutions must update their recovery plans at least annually or after a substantial change, while competent authorities may require institutions to update their recovery plans more frequently. There is a separate requirement at group level for parent undertakings to draw up and submit to the consolidating supervisor a group recovery plan in accordance with Article 7(1) of the

\footnotetext{
This applies to the Estonian law also - see the Financial Crisis Prevention and Resolution Act, §36(4)(1).

Impact Assessment (see Note 9), p. 8.

Ibid., p. 64.

Ibid.

19 The scope of the BRRD covers more entities than credit institutions alone, although this paper is limited to considering credit institutions only. For the list of entities covered, see the BRRD's Art. 1(1) and the corresponding points of Art. 2(1).
} 
BRRD. At both individual-institution level and group level, the recovery plan must comprise several specific elements unless the institution has been allowed by the competent authority to exclude some of them. ${ }^{{ }^{2} 2}$

The authors of the BRRD had in mind the idea of recovery plans as a way to ensure that banks have strategies in place that enable them to take early action to restore their long-term viability in the event of a material deterioration of their financial situation, while recovery plans should make it less likely that a bank ends up requiring intervention in its affairs. ${ }^{* 1}$ The name 'recovery plan' is self-explanatory; the main purpose is, of course, to plan the recovery. But, as there are various rules and requirements the recovery plan must comply with, it cannot be just a formal document with arbitrary content. These requirements are laid down foremost in the BRRD, national legislation, and the guidelines of the European Banking Authority (EBA). ${ }^{* 2}$

One can identify three important principles that must be considered in drafting and assessment of the recovery plan. The first of these, found in Recital 21 to the BRRD, is that the recovery plans should be detailed and based on realistic assumptions applicable in a range of robust and severe scenarios. Article 5(6) of the BRRD states that recovery plans have to contemplate a range of scenarios of severe macroeconomic and financial stress relevant to the institution's specific conditions including system-wide events and stress specific to individual legal persons and to groups and that these plans must include appropriate conditions and procedures to ensure the timely implementation of recovery actions as well as a wide range of recovery options. From this a presumption can be deduced that recovery plans should be realistic and precise plans of action presenting thought-through substance, realistic steps, and achievable goals. Also, a recovery plan should include provisions for real sources of additional liquidity or funds, and, therefore, institutions may be forced to make prior arrangements involving contracts to ensure availability of the resources needed in the event of applying the recovery plan. This principle is illustrated by Article 9(1) of the BRRD, dealing with the points at which the appropriate actions referred to in the plan may be taken. Further, the EBA has published guidelines on the minimal list of qualitative and quantitative recovery plan indicators. ${ }^{*} 3$

The second principle can be found in the same BRRD recital as the first: a recovery plan should be applied proportionately, reflecting the systemic importance of the institution or the group and its interconnectedness, including through mutual guarantee schemes. Although proportionality is regarded as a general principle of $\mathrm{EU} \mathrm{law}^{* 24}$ laid down in the European Union Treaties ${ }^{*} 5$, the language lists particular aspects to be considered when one is assessing a recovery plan. This principle has been given its strongest material form in Article 4 of the BRRD, which refers to the possibility of the authorities applying simplified obligations for certain institutions with regard to recovery planning. Specification is provided by EBA guidelines on the application of simplified obligations. ${ }^{*} 26$ More specific emphasising of the proportionality principle is found in Article 6(7) of the BRRD, regarding measures that competent authorities are permitted to take after the assessment of recovery plans. On one hand, the more important a credit institution or a group is systemically, the more comprehensive its recovery plan should be, and more rigorous measures on the competent authority's part are foreseen accordingly. At the same time, it lays down conditions and points of discretion for relieving some institutions of certain obligations.

The meaning and limits of resolution planning can be derived from the third principle - according to BRRD Article 5(3) recovery plans shall not assume any access to or receipt of extraordinary public financial support. The logic clearly proceeds from the above-mentioned purposeful aim for the recovery and resolution system to avoid using taxpayer money as much as possible, and this distinguishes recovery phase from resolution phase, where using public funds is not out of the question. ${ }^{* 27}$

20 For the minimal list of elements, see the BRRD's Art. 5(5), Art. 7(5), and Annex A.

21 Impact Assessment (see Note 9), pp. 64, 94.

22 The EBA is an independent EU body that does not supervise the subject institutions per se but does have important guidance, standard-setting, and legislative roles, along with some tasks related to oversight of national authorities. See Regulation (EU) No 1093/2010 of the European Parliament and of the Council of 24 November 2010, establishing a European Supervisory Authority (European Banking Authority) [2010] OJ L 331/12, Art. 1(1) and articles 2, 3, 8, 9, 10, 15, 16, and 173.

23 EBA guidelines on the minimum list of qualitative and quantitative recovery plan indicators of $23 \mathrm{July} 2015, \mathrm{EBA} / \mathrm{GL} / 2015 / 02$.

24 Tor-Inge Harbo, 'The Function of the Proportionality Principle in EU Law' [2010], Vol. 16, No. 2, March 2010, European Law Journal pp. 158, 159. - DOI: https://doi.org/10.1111/j.1468-0386.2009.00502.x.

25 Consolidated version of the Treaty on European Union [2012] OJ C 326/13, Art. 5(1) and 5(4); Protocol (No. 2) on the application of the principles of subsidiarity and proportionality [2012] OJ C 326/206.

26 EBA guidelines on the application of simplified obligations under Article 4(5) of Directive 2014/59/EU of 16 October 2016, $\mathrm{EBA} / \mathrm{GL} / 2015 / 16$.

27 See, for example, government financial stabilisation tools and public equity support tools in the BRRD's articles 56 and 57. 


\subsection{Supervision over obligations related to recovery plans}

As mentioned, the institutions are responsible for drawing up recovery plans themselves, but these plans are made subject to assessment by the competent authority, pursuant to Article 6 of the BRRD. More specifically, according to Article 6(1), institutions are required to submit their recovery plans to the competent authorities for complete assessment. According to Article 6(2)(a) of the BRRD and the directive's Recital 21, that assessment includes evaluating whether the plan is comprehensive and is reasonably likely to maintain or restore the institution's viability, and the financial position of the institution or of the group, taking into account the preparatory measures that the institution has taken or has planned to take. Also, under Article 6(2)(b) of the BRRD, the process includes examining whether the plan and specific options within the plan are reasonably likely to be implemented quickly and effectively in situations of financial stress and avoiding to the maximum extent possible any significant adverse effect on the financial system, including in scenarios which would lead other institutions to implement recovery plans within the same period. According to Article 8(1) and 8(2) of the BRRD, the review and assessment of group recovery plans are a joint responsibility of the consolidating supervisor and competent authorities of subsidiaries, but Article 8(3) of the BRRD clarifies that in the absence of a joint decision the final responsibility lies with the consolidating supervisor.

It is important to note that the competent authorities do not have the capacity to change the recovery plans themselves. Compelling changes to recovery plans is structured as a multi-level process, which is set out in articles 5 and 6 of the BRRD. According to the respective provisions, if a recovery plan is assessed to have deficiencies, the competent authorities have the power to require the institution to submit a revised plan. Next, if the problems persist in the revised plan, the competent authority may direct the institution to make specific changes to the plan. If this nevertheless results in absent or adequate recovery plan, the competent authority may then direct the institution to reduce the risk profile of the institution, including liquidity risk; to enable timely recapitalisation measures; to review the institution's strategy and structure; to make changes to the funding strategy so as to improve the resilience of the core business lines and critical functions; or to make appropriate changes to the governance structure of the institution. While the competent authority may not change the recovery plan, it therefore does possess levers for adjusting the institution's business and structure in response to the recovery plan submitted.

\section{Early intervention measures}

It is still very much possible that, irrespective of meticulous compliance with prudential requirements, the financial situation of an institution continues to deteriorate. Early intervention is the active phase after preparatory resolution planning and is tied to resolution plans being the means of activating a resolution plan. From Recital 40 to the BRRD it can be seen that the aim is to remedy the deterioration of an institution's financial and economic situation before that institution reaches a point at which the authorities have no other alternative than to resolve it. According to the impact assessment of the BRRD, the early intervention mechanism was designed for the competent authorities' use to oblige banks to undertake certain measures to avert major problems while leaving the control of the institution in the hands of its management. ${ }^{{ }^{2} 8}$ This stands in stark contrast to the essence envisioned for the resolution process, wherein the authorities may take charge of the decisions on business operations. ${ }^{{ }^{2} 29}$ The early intervention measures represent the competent authorities' powers to force an institution to act in various ways and are available if the financial condition of an institution is rapidly deteriorating or that institution is infringing or is likely to infringe specific requirements of prudential or investment services legislation. ${ }^{*} 30$

Considered in a wider context, the early intervention powers referred to in the BRRD's Recital 40 have been understood as not limited to the measures provided for by the BRRD; they are deemed to encompass also those already provided for in CRD IV for other circumstances. In this wider view, all possible actions that competent authorities direct at failing institutions before resolution actions could be considered early

\footnotetext{
Impact Assessment (see Note 9), p. 83.

29 Ibid.

30 See BRRD, Art. 27; EBA guidelines on triggers for use of early intervention measures pursuant to Article 27(4) of Directive 2014/59/EU of 29 July 2015, EBA/GL/2015/03.
} 
intervention measures. ${ }^{*}{ }^{1}$ The question is whether and, if so, how the measures in the BRRD broaden the powers derived from pre-existing EU prudential supervision legislation: CRD IV, the Capital Requirements Regulation, and the Single Supervisory Mechanism (SSM) Regulation ${ }^{*}{ }^{*}$ as the basis of EU prudential supervision legislation. ${ }^{*} 3$ The EU's harmonised fundamental prudential rules are formed by CRD IV and the Capital Requirements Regulation, while Article 2(9) and Article 6 of the SSM Regulation created the SSM and that regulation's Articles 1, 4, and 5 and Chapter III gave the European Central Bank the prudential supervisory powers.

The first early intervention measure, set out in Article 27(1)(a) of the BRRD, covers the right to require that the management body of the institution shall implement one or more of the arrangements or measures set out in the recovery plan or to update such a recovery plan when the circumstances that led to the early intervention are different from the assumptions set out in the initial recovery plan. It covers also the right to require implementation of one or more of the arrangements or measures set out in the updated plan within a specific timeframe. In short, the competent authority can require an institution to activate parts of the recovery plan or require updating the plan. Given that this is explicitly provided for by neither CRD IV nor the Capital Requirements Regulation and in consideration of its nature, one can consider this measure recovery-specific.

The second measure, set out in Article 27(1)(b) of the BRRD, is much milder and more general: the management body of the institution may be compelled to examine the situation, identify measures to overcome any problems identified, and draw up an action programme to overcome those problems and a timetable for its implementation. This can be viewed as exercising a power to force an institution into action, but, as it gives free hands to the institution and to the same management who led the institution into trouble, the measure's effectiveness on its own could obviously be disputed. The measure in question greatly resembles the supervisory power provided under the prudential framework to require institutions to present a plan to restore compliance with the requirements of CRD IV or the Capital Requirements Regulation, specified in Article 104(1)(c) of CRD IV, and with other relevant supervisory requirements as set out in Article 16(2)(c) of the SSM Regulation. The measure therefore broadens the powers from those available under CRD IV in situations wherein the institution is not yet in breach of the prudential requirements.

The third early intervention measure, provided for by Article 27(1)(c) of the BRRD, is to require the management body of the institution to convene, or if the management body fails to comply with that requirement convene directly, a meeting of shareholders of the institution. The competent authority may set theand in both cases set the agenda and require certain decisions to be considered for adoption by the shareholders. Here, the responsibility for the decision is put on the highest decision-making body of the institution while the competent authority retains the guiding role. There is no such tool provided under the above-mentioned EU prudential legislation. The recovery system seems to shift the boundaries for possible guidance and direction by the competent authority through institution's shareholders.

Set out in Article 27(1)(d) of the BRRD, the fourth measure entails requiring that one or more members of the management body or senior management be removed or replaced if found unfit to perform their duties pursuant to Article 13 of CRD IV or Article 9 of Directive 2014/65/EU. As is implied by the direct reference to the sources of the obligations, this is not a novel or a BRRD-specific measure, and indeed it is included in the toolbox of prudential supervision in the form of Article 16(2)(m) of the SSM Regulation.

Article 27(1)(e) of the BRRD sets out the fifth measure, which is a more specific one: requiring the management body of the institution to draw up a plan for negotiation on restructuring of debt with some or all of its creditors in according to the recovery plan, where applicable. The harmonised EU prudential supervision framework does not feature this specific tool for supervisors. This renders it a recovery-specific measure. However, the prudential supervision legislation does, to some degree, provide for the next two early intervention measures mentioned in Article 27(1)(f) and 27(1)(g) of the BRRD, respectively: to require

31 In national legislation, the national supervisor's powers can be formulated quite broadly, irrespective of the EU legislation. For example, the Estonian supervisory authority has a general right to make demands for compliance with legislation regulating the operation of a credit institution. See Krediidiasutuste seadus (Credit Institutions Act). RT I 1999, 23, 349; RT I, 13.03.2019 98 (in Estonian; English text available at https://www.riigiteataja.ee/en/eli/501042019006/consolide, accessed on 30 April 2019), §104(1)(15).

32 Council Regulation (EU) No 1024/2013 of 15 October 2013 conferring specific tasks on the European Central Bank concerning policies relating to the prudential supervision of credit institutions [2013] OJ L 287/63 (the SSM Regulation).

33 It is possible that similar powers may be derived from other EU or national legislative acts, not covered in this article. 
changes to the institution's business strategy and to require changes to the legal or operational structures of the institution. CRD IV Article 104(1)(b) provides for a supervisory power to require reinforcement of the arrangements, processes, mechanisms, and strategies implemented in accordance with articles 73 and 74 . The SSM Regulation's Article 16(2)(b) provides for powers to require reinforcement of these four. As Article 73 of CRD IV deals with strategies to assess and maintain internal capital and Article 74 with governance arrangements, and the SSM Regulation does not grant explicit power to require changes in legal structures, the powers conferred on the competent authorities by the recovery system could be interpreted to be somewhat broader.

The final early intervention measure, set out in 27(1)(h) of the BRRD, involves the power to acquire, including through on-site inspections and provide to the resolution authority, all the information necessary in order to update the resolution plan and prepare for the possible resolution of the institution and for valuation of the assets and liabilities of the institution in accordance with Article 36 of the BRRD. In essence, the power to obtain information from the institution reiterates the power to obtain the information needed for prudential supervision laid down in articles 4(3) and 65(3) of CRD IV and Article 10 of the SSM Regulation.

Besides explicit early intervention measures, there are two competent authority powers that are not in the same list of designated early intervention measures per se but are closely related to them and have the same purpose. Firstly, according to Article 28 of the BRRD, the competent authority may, if the above named measures are not sufficient to reverse the deterioration of the institution, require the removal of the senior management or management body of the institution, in its entirety or with regard to individuals. The main difference from the similar measure of Article 27(1)(d) of the BRRD, covered above, is the absence of the prerequisite of the member or management body being unfit for the duties. Secondly, if this still proves insufficient, the competent authorities may, according to Article 29 of the BRRD, appoint one or more temporary administrators for the institution themselves. A temporary administrator can be appointed either to temporarily replace the management body or to temporarily work with the management body, with the powers, role and functions, and term of the temporary administrator being determined by the competent authority. As one can clearly see, these powers entail direct involvement in the internal affairs of the institution, depriving the bodies normally entitled to appoint the managers of their right and powers to do so. On the other hand, this is not a power to interfere in the business decisions; its exercise changes only the management. These two measures are also structurally part of Title III of the BRRD, which covers early intervention, and constitute a subset of the powers available to the competent authority before the resolution authority's powers and resolution process. These go a step further than the early intervention measures, and the powers are broadened in certain situations, but they still do not cross the line between the competent authority's powers and the resolution authority's. Therefore, structurally and functionally these two tools should, more likely than not, be considered part of the recovery proceedings.

\section{Conclusions}

This article has explored the question of whether recovery of credit institutions could be considered a differentiable concept in the BRRD. It can be concluded that indeed, recovery in the sense applied in the BRRD can be distinguished from the pre-existing prudential framework and the concept of resolution on the basis of function and can be usefully treated as a separate concept. In its function, it stands between the pre-existing prudential framework on one hand and the resolution framework on the other. Recovery of credit institutions can be considered to consist of regulations regarding recovery planning, early intervention measures, and two measures not addressed by the starting proposition for this article: the power to remove the senior management or management body without the constraints of the similar resolutionlinked measure and the power to appoint a temporary administrator. With regard to the timeline, the order of application of the relevant regulation is prudential-recovery-resolution. However, it is not out of the question that prudential and recovery actions could, to some extent, overlap - with the recovery planning taking place in parallel with application of the prudential regulations and early intervention measures getting applied in conjunction with prudential supervisory powers.

Recovery plans are directly linked to the other main element of recovery, early intervention measures, through the measures activating the plan or parts of it. This article submits that, while some early 
intervention measures are recovery-specific and broaden the supervisory powers significantly, some do not. If recovery were not be meant to be considered a separate phenomenon, the overlap of powers between prudential supervision and recovery would not be needed. As indicated in the introduction, the principles and rules applicable to exercising powers that exist in parallel under prudential and recovery regulations could differ between the two sets. Various issues remain for further consideration, for example infringement of rules and principles specific to recovery could bear consequences with regard to liability of the authorities, but this is a subject for future papers. 